\section{Promotion of Flowering from Far-red Radiation Depends on the Photosynthetic Daily Light Integral}

\author{
W. Garrett Owen, Qingwu Meng, and Roberto G. Lopez ${ }^{1}$ \\ Department of Horticulture, Michigan State University, East Lansing, MI \\ 48824
}

Additional index words. annual bedding plants, day-extension lighting, DLI, light-emitting diodes, LEDs, long-day, photoperiod, short-day

\begin{abstract}
Under natural short days, growers can use photoperiodic lighting to promote flowering of long-day plants and inhibit flowering of short-day plants. Unlike traditional lamps used for photoperiodic lighting, low-intensity light-emitting diode (LED) lamps allow for a wide array of adjustable spectral distributions relevant to regulation of flowering, including red $(R)$ and white $(W)$ radiation with or without far-red (FR) radiation. Our objective was to quantify how day-extension (DE) photoperiodic lighting from two commercially available low-intensity LED lamps emitting $\mathbf{R}+\mathbf{W}$ or $\mathbf{R}+\mathbf{W}+\mathbf{F R}$ radiation interacted with daily light integral (DLI) to influence stem elongation and flowering of several ornamental species. Long-day plants [petunia (Petunia $\times$ hybrida Vilm.-Andr. 'Dreams Midnight') and snapdragon (Antirrhinum majus L. 'Oh Snap Pink')], short-day plants [african marigold (Tagetes erecta L. 'Moonsong Deep Orange') and potted sunflower (Helianthus annuus L. 'Pacino Gold')], and day-neutral plants [pansy (Viola $\times$ wittrockiana Gams. 'Matrix Yellow') and zinnia (Zinnia elegans Jacq. 'Magellan Cherry')] were grown at 20/18 ${ }^{\circ} \mathrm{C}$ day/night air temperatures and under low $\left(6-9 \mathrm{~mol} \cdot \mathrm{m}^{-2} \cdot \mathrm{d}^{-1}\right)$ or high $\left(16-19 \mathrm{~mol} \cdot \mathrm{m}^{-2} \cdot \mathrm{d}^{-1}\right)$ seasonal photosynthetic DLIs from ambient solar radiation combined with supplemental high-pressure sodium lighting and DE LED lighting. Photoperiods consisted of a truncated 9-hour day (0800-1700 HR) with additional 1-hour (1700-1800 HR, 10 hours total), 4-hour (1700-2100 HR, 13 hours total), or 7-hour (1700-2400 HR, 16 hours total) $\mathbf{R}+\mathrm{W}$ or $\mathbf{R}+\mathrm{W}+\mathrm{FR}$ LED lighting at $2 \mu \mathrm{mol} \cdot \mathrm{m}^{-2} \cdot \mathrm{s}^{-1}$. Days to visible bud, plant height at first open flower, and time to first open flower (TTF) of each species were influenced by DLI, lamp type, and photoperiod though to different magnitudes. For example, plant height of african marigold and potted sunflower at first open flower was greatest under R + W + FR lamps, high DLIs, and 16-hour photoperiods. Petunia grown under $R+W$ lamps, high DLI, and 10- and 13-hour photoperiods were the most compact. For all species, TTF was generally reduced under high DLIs. For example, regardless of the lamp type, flowering of african marigold occurred fastest under a high DLI and 10hour photoperiod. Flowering of petunia and snapdragon occurred fastest under a high DLI, R + W + FR lamps, and a 16-hour photoperiod. However, only under high DLIs, $R+W$ or $R+W+F R$ lamps were equally effective at promoting flowering when used to provide DE lighting. Our data suggest that under low DLIs, flowering of long-day plants (petunia and snapdragon) occurs more rapidly under lamps providing $\mathbf{R}+\mathbf{W}+\mathbf{F R}$, whereas under high DLIs, flowering is promoted similarly under either $\mathbf{R}+\mathbf{W}$ or $\mathbf{R}+\mathbf{W}+\mathbf{F R}$ lamps.
\end{abstract}

Photoperiod is an environmental signal that controls bud dormancy and break, tuber formation, and flowering. A photoperiodic response, such as flowering, is determined primarily by the duration of the dark period

Received for publication 2 Oct. 2017. Accepted for publication 2 Feb. 2018.

We thank Ball Horticultural Co. for seeds; Sun Gro Horticulture for substrate; Everris NA, Inc. for fertilizer; Philips Lighting and Hort Americas for LED lamps; and the USDA-NIFA SCRI grant no. 2010-51181-21369 and the USDA-ARS Floriculture and Nursery Research Initiative for funding.

The use of trade names in this publication does not imply endorsement by Michigan State University of products named nor criticism of similar ones not mentioned.

${ }^{1}$ Corresponding author. E-mail: rglopez@msu.edu. greenhouse growers can use low-intensity electric lighting to shorten long nights and promote or inhibit flowering of long- or short-day plants, respectively. Accelerating flowering of long-day plants shortens production time, whereas delaying flowering of short-day plants is often accompanied by desirable vegetative growth. Electric lighting is typically delivered at the beginning of the night (i.e., as DE lighting) or in the middle of the night [i.e., night-interruption (NI) lighting]. The minimum duration to operate electric lighting varies among plant species and cultivars because of their different critical skotoperiods. Generally, DE lighting creating a 16-h day or 4-h NI lighting is effective for most ornamental crops (Runkle et al., 1998; Whitman et al., 1998).

The spectral distribution of photoperiodic lighting influences regulation of flowering in photoperiodic crops. Red [R $(600-700 \mathrm{~nm})]$ and far-red [FR (700-800 $\mathrm{nm})$ ] radiation can mediate activities of phytochrome $B$ and phytochrome A. Red radiation converts phytochrome from an inactive form, $P_{\mathrm{R}}$, to an active form, $P_{\mathrm{FR}}$, whereas FR radiation can at least partially reverse $\mathrm{R}$ radiation effects by converting $P_{\mathrm{FR}}$ back to $P_{\mathrm{R}}$ (Thomas and Vince-Prue, 1997). A combination of $\mathrm{R}$ and FR radiation promotes flowering of a variety of long-day plants (Craig and Runkle, 2016; Thomas and Vince-Prue, 1997), whereas R radiation is the major waveband for inhibition of flowering in short-day plants (Craig and Runkle, 2013). Blue [B (400-500 nm)] radiation mediates both phytochrome and cryptochrome activities and can regulate flowering, but only when its intensity is sufficiently high (i.e., $\geq 30 \mu \mathrm{mol} \cdot \mathrm{m}^{-2} \cdot \mathrm{s}^{-1}$ ) (Meng and Runkle, 2017).

Incandescent, compact fluorescent, and high-intensity discharge (HID) lamps are light sources traditionally used for photoperiodic control of flowering in greenhouses. However, most incandescent lamps have been phased out of production because of their energy inefficiency and short life span. Compact fluorescent and HID lamps have spectral distributions deficient in FR radiation, which is crucial for rapid flowering of some long-day plants (Blanchard and Runkle, 2010; Runkle et al., 2012). The emergence of long-lasting, energy-efficient LEDs allows for a wide array of adjustable spectral distributions relevant to regulation of flowering. Lighting manufacturers have developed LED lamps emitting varying intensities of $\mathrm{B}, \mathrm{R}$, or FR radiation for flowering applications of photoperiodic ornamental crops.

The photosynthetic DLI is the accumulated photosynthetic photon flux density $[P P F D(400-700 \mathrm{~nm})]$ in $1 \mathrm{~d}$. A DLI increase from 5 to $20 \mathrm{~mol} \cdot \mathrm{m}^{-2} \cdot \mathrm{d}^{-1}$ can hasten flowering and increase flower number and dry mass of plants such as petunia $(P$. $\times$ hybrida Vilm.-Andr.) and french marigold (Tagetes patula L.) (Faust et al., 2005; Moccaldi and Runkle, 2007). In addition, the DLI may influence the role of FR radiation in promotion of flowering in some long-day plants such as petunia. For example, the addition 
of $\mathrm{FR}$ radiation to $\mathrm{R}$ and $\mathrm{W}$ radiation in NI lighting promoted flowering of some ornamental species grown under a low DLI $\left(\leq 6 \mathrm{~mol} \cdot \mathrm{m}^{-2} \cdot \mathrm{d}^{-1}\right)$, but not under a higher DLI $\left(<12 \mathrm{~mol} \cdot \mathrm{m}^{-2} \cdot \mathrm{d}^{-1}\right)$ (Kohyama et al., 2014). However, this discovery was based on two experimental replications with different DLIs and therefore, warrants additional research on the interaction between the DLI and FR radiation. Our objective was to quantify how DE photoperiodic lighting from two commercially available low-intensity LED lamps emitting $\mathrm{R}+\mathrm{W}$ or $\mathrm{R}+\mathrm{W}+\mathrm{FR}$ radiation would interact with the DLI to influence stem elongation and flowering of several long-day, short-day, and day-neutral ornamental species.

\section{Materials and Methods}

Plant material and culture. Seeds of pansy 'Matrix Yellow', petunia 'Dreams Midnight', and snapdragon 'Oh Snap Pink' were sown into 288-cell (6-mL individual cell volume) plug trays. Seeds of african marigold 'Moonsong Deep Orange', potted sunflower 'Pacino Gold', and zinnia 'Magellan Cherry' (Ernst Benary America, Inc., DeKalb, IL) were sown into 72-cell (30.7-mL individual cell volume) plug trays. All seeds were sown into plug trays filled with a commercial soilless medium comprising (by volume) $65 \%$ peat, $20 \%$ perlite, and $15 \%$ vermiculite (Super Fine Germinating Mix; Sun Gro Horticulture, Agawam, MA) and were covered with a thin layer of vermiculite (Sunshine; SunGro Horticulture, Bellevue, WA) to maintain moisture.

Seedling greenhouse environment. Plug trays were placed and seedlings were grown in a glass-glazed greenhouse with exhaust fans and evaporative cooling pads, radiant hot water heat, and retractable shade curtains controlled by an environmental control system (Maximizer Precision 10; Priva North America, Vineland Station, Canada). Throughout the study, air temperature was measured every $10 \mathrm{~min}$ by an aspirated Priva temperature sensor at plant height and recorded by the computer control system (Priva North America). The greenhouse day and night air temperature set points were 20/ $18{ }^{\circ} \mathrm{C}$. To inhibit flower induction, pansy, petunia, and snapdragon seedlings were placed under a noninductive 10 -h photoperiod, whereas african marigold, potted sunflower, and zinnia seedlings were grown under a noninductive 16-h photoperiod. Quantum sensors (Model LI-190R; LI-COR, Inc., Lincoln, NE) were placed at the canopy level to record the PPFD. For each treatment, the $P P F D$ was measured every $15 \mathrm{~s}$, averaged, and logged every $15 \mathrm{~min}$ by a data logger (Model CR1000; Campbell Scientific, Inc., Logan, UT). Mean greenhouse day/night air temperatures $( \pm S D)$ during seed germination were $20.3 \pm 1.2 / 18.0$ $\pm 1.7^{\circ} \mathrm{C}, 20.4 \pm 1.6 / 18.2 \pm 1.2^{\circ} \mathrm{C}, 21.5 \pm 1.2 /$ $19.6 \pm 1.4^{\circ} \mathrm{C}$, and $21.6 \pm 1.8 / 19.5 \pm 1.7^{\circ} \mathrm{C}$ for the low DLI (Rep 1), low DLI (Rep 2), high
DLI (Rep 1), and high DLI (Rep 2) treatments, respectively.

Irrigation water was supplemented with 93\% sulfuric acid (Brenntag, Reading, PA) at $0.08 \mathrm{mg} \cdot \mathrm{L}^{-1}$, which reduced alkalinity from 400 to $100 \mathrm{mg} \cdot \mathrm{L}^{-1}$ calcium carbonate. Seedlings were irrigated with acidified water supplemented with water-soluble fertilizer (Jack's LX 16N-0.94P-12.3K Plug Formula for High Alkalinity Water; J.R. Peters, Inc., Allentown, PA) providing (in $\mathrm{mg} \cdot \mathrm{L}^{-1}$ ): 100 $\mathrm{N}, 10 \mathrm{P}, 78 \mathrm{~K}, 18 \mathrm{Ca}, 9.4 \mathrm{Mg}, 0.10 \mathrm{~B}, 0.05 \mathrm{Cu}$, $0.50 \mathrm{Fe}, 0.25 \mathrm{Mn}, 0.05 \mathrm{Mo}$, and $0.25 \mathrm{Zn}$.

Transplant culture. After $35 \mathrm{~d}$ from seed sow, pansy, petunia, and snapdragon were transplanted into $11.4-\mathrm{cm}(600-\mathrm{mL})$ round containers. After $28 \mathrm{~d}$ from seed sow, african marigold, potted sunflower, and zinnia were transplanted into $12.7-\mathrm{cm}(885-\mathrm{mL})$ diameter containers. All containers were filled with a commercial soilless medium comprising (by volume) $65 \%$ peat, $20 \%$ perlite, and $15 \%$ vermiculite (Fafard 2; Sun Gro Horticulture). Three days after transplant, snapdragon seedlings were thinned to one seedling per pot by excising extra seedlings at the substrate surface.

The plants were irrigated as necessary with acidified water supplemented with a combination of two water-soluble fertilizers $(3: 1$ mixture of $15 \mathrm{~N}-2.2 \mathrm{P}-12.5 \mathrm{~K}$ and $21 \mathrm{~N}-2.2 \mathrm{P}-16.6 \mathrm{~K}$, respectively; Everris, Marysville, $\mathrm{OH}$ ) to provide the following $\left(\mathrm{mg} \cdot \mathrm{L}^{-1}\right): 200 \mathrm{~N}, 26 \mathrm{P}, 163 \mathrm{~K}, 50 \mathrm{Ca}, 20$ $\mathrm{Mg}, 1.0 \mathrm{Fe}, 0.5 \mathrm{Mn}$ and $\mathrm{Zn}, 0.24 \mathrm{Cu}$ and $\mathrm{B}$, and $0.1 \mathrm{Mo}$.

Day-extension photoperiod treatments. An automatic blackout curtain system with an opaque black interior and reflective exterior (VRE Greenhouse Systems, Stoney Creek, Canada) was used to create and control the photoperiod. Each day, blackout curtains were retracted and closed to create a truncated 9-h (0800-1700 HR) photoperiod consisting of natural daylengths with supplemental lighting from high-pressure sodium lamps (e-system HID; PARSource,
Petaluma, CA) that delivered a $P P F D$ of $\approx 70 \mu \mathrm{mol} \cdot \mathrm{m}^{-2} \cdot \mathrm{s}^{-1}$ at plant height. Two commercially available low-intensity LED lamps emitting $\mathrm{R}+\mathrm{W}+\mathrm{FR}$ or $\mathrm{R}+\mathrm{W}$ radiation (GreenPower LED flowering lamp; Philips, Eindhoven, Netherlands) were used to extend the photoperiod by $1 \mathrm{~h}[10 \mathrm{~h}$; (1700-1800 HR)], $4 \mathrm{~h}$ [13 h; (1700-2100 HR)], or $7 \mathrm{~h}$ [16 h; (1700-2400 HR)]. The 100-nm waveband ratios of the $\mathrm{R}+\mathrm{W}$ and $\mathrm{R}+\mathrm{W}+$ FR lamps, defined by their relative photon flux densities of $\mathrm{B}$, green, $\mathrm{R}$, and FR radiation, were $6: 14: 78: 1$ and $6: 13: 35: 46$, respectively. In each DE photoperiod treatment, two $\mathrm{R}+\mathrm{W}$ or $\mathrm{R}+\mathrm{W}+\mathrm{FR}$ lamps were installed $1.2 \mathrm{~m}$ above the bench, delivering a total photon flux density $(T P F D)$ of $\approx 10$ $\mu \mathrm{mol} \cdot \mathrm{m}^{-2} \cdot \mathrm{s}^{-1}$ between 400 and $800 \mathrm{~nm}$. Light intensity at plant level was adjusted by installing a neutral-density metal mesh (General Purpose Aluminum; New York Wire, Grand Island, NY) around the fixtures, so each lamp provided a similar TPFD $\approx 2$ $\mu \mathrm{mol} \cdot \mathrm{m}^{-2} \cdot \mathrm{s}^{-1}$. The plants were spaced on 20 -cm centers in each DE photoperiod treatment. The spectral distribution of the LED lamps was measured using a spectroradiometer (BLUE-Wave Miniature Spectrometer; StellarNet, Inc., Tampa, FL) in six locations under each lamp. The phytochrome photoequilibria were estimated according to Sager et al. (1988) (Fig. 1).

Greenhouse environment. The plants were grown in a glass-glazed greenhouse as previously described. The greenhouse day/night air temperature $(12 \mathrm{~h} / 12 \mathrm{~h})$ set points were $20 / 18{ }^{\circ} \mathrm{C}$. Throughout the study, air temperature and $P P F D$ were recorded as previously described. The mean greenhouse DLIs for each replication are reported in Table 1. Mean day/night air temperatures were $20.1 \pm 1.5 / 18.2 \pm$ $2.1{ }^{\circ} \mathrm{C}, 20.5 \pm 1.1 / 18.5 \pm 1.6{ }^{\circ} \mathrm{C}, 21.0 \pm$ $1.8 / 19.3 \pm 1.8^{\circ} \mathrm{C}$, and $21.1 \pm 2.1 / 19.4 \pm 1.9^{\circ} \mathrm{C}$ for the low DLI (Rep 1), low DLI (Rep 2), high DLI (Rep 1), and high DLI (Rep 2) treatments, respectively.

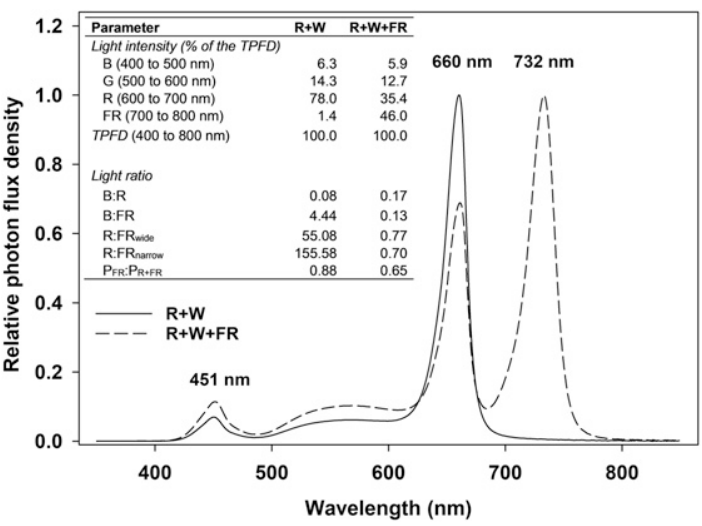

Fig. 1. Spectral distribution, intensity of blue $[B(400-500 \mathrm{~nm})]$, green $[\mathrm{G}(500-600 \mathrm{~nm})]$, red $[R(600-700 \mathrm{~nm})]$, and far-red [FR (700-800 nm)] radiation, total photon flux density (TPFD), light ratio, and estimated phytochrome photoequilibria $\left[P_{\mathrm{FR}} / P_{\mathrm{R}+\mathrm{FR}}\right.$ (the proportion of FR-absorbing phytochromes in the pool of R- and FR-absorbing phytochromes; Sager et al., 1988)] of R + white (W) (solid line) and R + W + FR light-emitting diode (dashed line) lamps without wire mesh. R:FR $\mathrm{Fide}_{\text {wide }}$ walculated as $600-700$ $\mathrm{nm}: 700-800 \mathrm{~nm}$; R:FR narrow was calculated as $655-665 \mathrm{~nm}: 725-735 \mathrm{~nm}$. 
Table 1. Average greenhouse daily light integral (DLI) under low or high photosynthetic DLIs and dayextension photoperiodic lighting delivered from two light-emitting diode (LED) lamp types for each replication. The LEDs delivered red + white $(\mathrm{R}+\mathrm{W})$ or red + white + far-red $(\mathrm{R}+\mathrm{W}+\mathrm{FR})$ radiation and were used to extend the photoperiod by $1 \mathrm{~h}[10 \mathrm{~h}(1700-1800 \mathrm{HR})], 4 \mathrm{~h}[13 \mathrm{~h}(1700-2100 \mathrm{HR})]$, or $7 \mathrm{~h}[16 \mathrm{~h}(1700-2400 \mathrm{HR})]$.

\begin{tabular}{|c|c|c|c|c|}
\hline Photoperiod (h) & LED lamp & Rep & DLI treatment & Avg greenhouse DLI $\left(\mathrm{mol} \cdot \mathrm{m}^{-2} \cdot \mathrm{d}^{-1}\right)$ \\
\hline \multirow[t]{4}{*}{10} & & 1 & Low & $\begin{array}{c}7.4 \pm 1.4 \\
\end{array}$ \\
\hline & & 2 & Low & $8.7 \pm 1.9$ \\
\hline & & 1 & High & $18.7 \pm 6.7$ \\
\hline & & 2 & High & $17.5 \pm 5.9$ \\
\hline \multirow[t]{4}{*}{13} & & 1 & Low & $6.8 \pm 1.5$ \\
\hline & & 2 & Low & $7.8 \pm 1.7$ \\
\hline & $\mathrm{R}+\mathrm{W}$ & 1 & High & $18.3 \pm 5.1$ \\
\hline & & 2 & High & $16.6 \pm 6.0$ \\
\hline \multirow[t]{4}{*}{16} & & 1 & Low & $6.5 \pm 1.3$ \\
\hline & & 2 & Low & $7.8 \pm 1.6$ \\
\hline & & 1 & High & $18.8 \pm 6.5$ \\
\hline & & 2 & High & $17.5 \pm 5.7$ \\
\hline \multirow[t]{4}{*}{10} & & 1 & Low & $6.5 \pm 1.3$ \\
\hline & & 2 & Low & $7.7 \pm 1.5$ \\
\hline & & 1 & High & $17.2 \pm 6.2$ \\
\hline & & 2 & High & $16.4 \pm 6.8$ \\
\hline \multirow[t]{4}{*}{13} & & 1 & Low & $7.3 \pm 1.2$ \\
\hline & & 2 & Low & $8.4 \pm 1.5$ \\
\hline & $\mathrm{R}+\mathrm{W}+\mathrm{FR}$ & 1 & High & $17.6 \pm 5.4$ \\
\hline & & 2 & High & $16.5 \pm 6.5$ \\
\hline \multirow[t]{4}{*}{16} & & 1 & Low & $7.0 \pm 1.4$ \\
\hline & & 2 & Low & $8.2 \pm 1.3$ \\
\hline & & 1 & High & $17.2 \pm 5.8$ \\
\hline & & 2 & High & $16.8 \pm 6.3$ \\
\hline
\end{tabular}

Data collection. The plants were monitored daily and the date of visible flower bud or inflorescence and first open flower was recorded when the flower buds were visible and the petals of the first flower were fully reflexed, respectively. At flowering, we measured plant height and counted the node number. Plant height was measured from the soilless medium surface to the top of the flower (african marigold, pansy, petunia, potted sunflower, and zinnia) or inflorescence (snapdragon). Node number was determined by counting the number of nodes below the first open flower. For each species and experimental unit (a single plant), time to visible bud (TVB) and TTF from transplant were calculated. Plants with no visible buds observed within $90 \mathrm{~d}$ after transplant were considered nonflowering.

Experimental design and data analysis. The experiment was a randomized block design with two DLIs, two LED lamp types, and three photoperiods as variables. Six experimental units were randomly distributed to each treatment within each of two blocks. The experiment was performed twice for each low or high DLI treatment. Data were pooled across two replications. Species were analyzed independently. Data were analyzed using SAS (SAS 9.4; SAS Institute, Inc., Cary, NC) mixed-model procedure (PROC MIXED) for analysis of variance. Mean separations among treatments were performed with Tukey's honest significant difference test $(P \leq 0.05)$.

\section{Results}

Time to visible bud. For african marigold, petunia, and snapdragon, TVB was influenced
Regardless of lamp type, snapdragon was shortest when grown under long days and high DLIs.

Time to first open flower. Time to flower of all species was influenced by DLI and in all instances was reduced under high DLIs (Fig. 2). Under low DLIs, R + W lamps did not accelerate flowering of petunia, pansy, snapdragon, and zinnia across photoperiods. For example, TTF of petunia grown under low DLIs, R + W lamps, and a 10-, 13-, or 16-h photoperiod were 53,52 , and $53 \mathrm{~d}$, respectively (Fig. 2). Under high DLIs and long-day photoperiods, TTF of petunia and snapdragon was significantly reduced, regardless of lamp type, compared with that of plants under low DLIs. For example, TTF of petunia grown under high DLIs and a 16-h photoperiod was 26 and $22 \mathrm{~d}$ for plants under $\mathrm{R}+\mathrm{W}$ and $\mathrm{R}+\mathrm{W}+\mathrm{FR}$ lamps, respectively. Under low DLIs and a 16-h photoperiod, TTF of petunia was 53 and $32 \mathrm{~d}$ for plants under $\mathrm{R}+\mathrm{W}$ and $\mathrm{R}+\mathrm{W}+\mathrm{FR}$ lamps, respectively. For african marigold and potted sunflower, flowering occurred fastest under high DLIs and a 10- or 13-h photoperiod, respectively, regardless of lamp type. Time to flower of pansy and zinnia was not influenced by photoperiod or lamp type except for pansy under high DLIs combined with a 13-h photoperiod.

\section{Discussion}

replication (Table 2). Under high DLIs, TVB of the long-day plants petunia and snapdragon was similar regardless of photoperiod or lamp type. For example, across all photoperiods, average TVB of petunia under high DLIs was 16 or $15 \mathrm{~d}$ under $\mathrm{R}+\mathrm{W}$ or R + W + FR lamps, respectively. However, under low DLIs, average TVB of petunia was delayed by $18 \mathrm{~d}$ under $\mathrm{R}+\mathrm{W}$ LED lamps compared with that of $\mathrm{R}+\mathrm{W}+$ FR lamps. No significant trends in TVB were observed for the short-day plant zinnia among treatments (Table 2). For pansy, TVB was influenced by lamp type and DLI, whereas for potted sunflower, TVB was influenced by photoperiod and DLI.

Node number at first open flower. For all six species, node number was influenced by DLI (Table 2). However, no significant trends in response to lamp type or photoperiod were observed for pansy, petunia, or zinnia. Generally, node number of the short-day plant african marigold increased under high DLIs and long days regardless of lamp type. Conversely, node number of petunia and snapdragon at first open flower was lower under high DLIs, regardless of lamp type and photoperiod.

Height at first open flower. For all six species, height was influenced by photoperiod and DLI (Table 2). Generally, plant height of the short-day plants african marigold, potted sunflower, and zinnia at first open flower was greatest under $\mathrm{R}+\mathrm{W}+\mathrm{FR}$ lamps, high DLIs, and 16-h photoperiods. Petunia grown under $\mathrm{R}+\mathrm{W}$ lamps, high DLI, and 10- or 13-h photoperiods was the most compact. In contrast, pansy grown under $\mathrm{R}+\mathrm{W}$ lamps and low DLIs was the most compact.
Based on flowering time in response to different photoperiods, the six crops in our study can be divided into three categories: long-day plants (petunia and snapdragon), short-day plants (african marigold and sunflower), and day-neutral plants (pansy and zinnia). High DLIs promoted flowering of all plant species except pansy compared with low DLIs. Pansy flowered earlier under higher DLIs only when grown under a 10-h photoperiod with additional FR radiation. These results are consistent with the notion that an elevated DLI can shorten time to flower in a variety of ornamental species such as zinnia 'Dreamland Rose' and cyclamen (Cyclamen persicum Mill.) (Faust et al., 2005; Oh et al., 2009). According to a multiple regression model based on the DLI and air temperature (Moccaldi and Runkle, 2007), TTF of african marigold grown under a 16-h photoperiod with $\mathrm{R}+\mathrm{W}$ LEDs in our study is predicted to decrease by $21 \%$ under high DLIs compared with low DLIs. Consistently, the actual percent decrease was $\approx 17 \%$, showing that the model can accurately predict TTF based on the DLI. Photosynthesis and flowering are closely associated; increased photosynthesis under high light can upregulate gene expression of FLOWERING LOCUS T (FT) to promote flowering in Arabidopsis (King et al., 2008). The product of photosynthesis, sucrose, is also an essential component of the floral stimulus (Corbesier et al., 1998; King et al., 2008; Sheldon et al., 2000). Therefore, promotion of flowering 
Table 2. Days to visible flower bud from transplant, node number, and stem length at first flower for six annual ornamental crops grown under low or high photosynthetic daily light integrals (DLIs) and day-extension photoperiodic lighting delivered from low-intensity light-emitting diode (LED) lamps delivering proportions $(\%)$ of red + white $(\mathrm{R}+\mathrm{W})$ or red + white + far-red $(\mathrm{R}+\mathrm{W}+\mathrm{FR})$ radiation were used to extend the photoperiod by $1 \mathrm{~h}[10 \mathrm{~h}(1700-1800 \mathrm{HR})], 4 \mathrm{~h}[13 \mathrm{~h}$ (1700-2100 HR)], or $7 \mathrm{~h}[16 \mathrm{~h}(1700-2400 \mathrm{HR})]$.

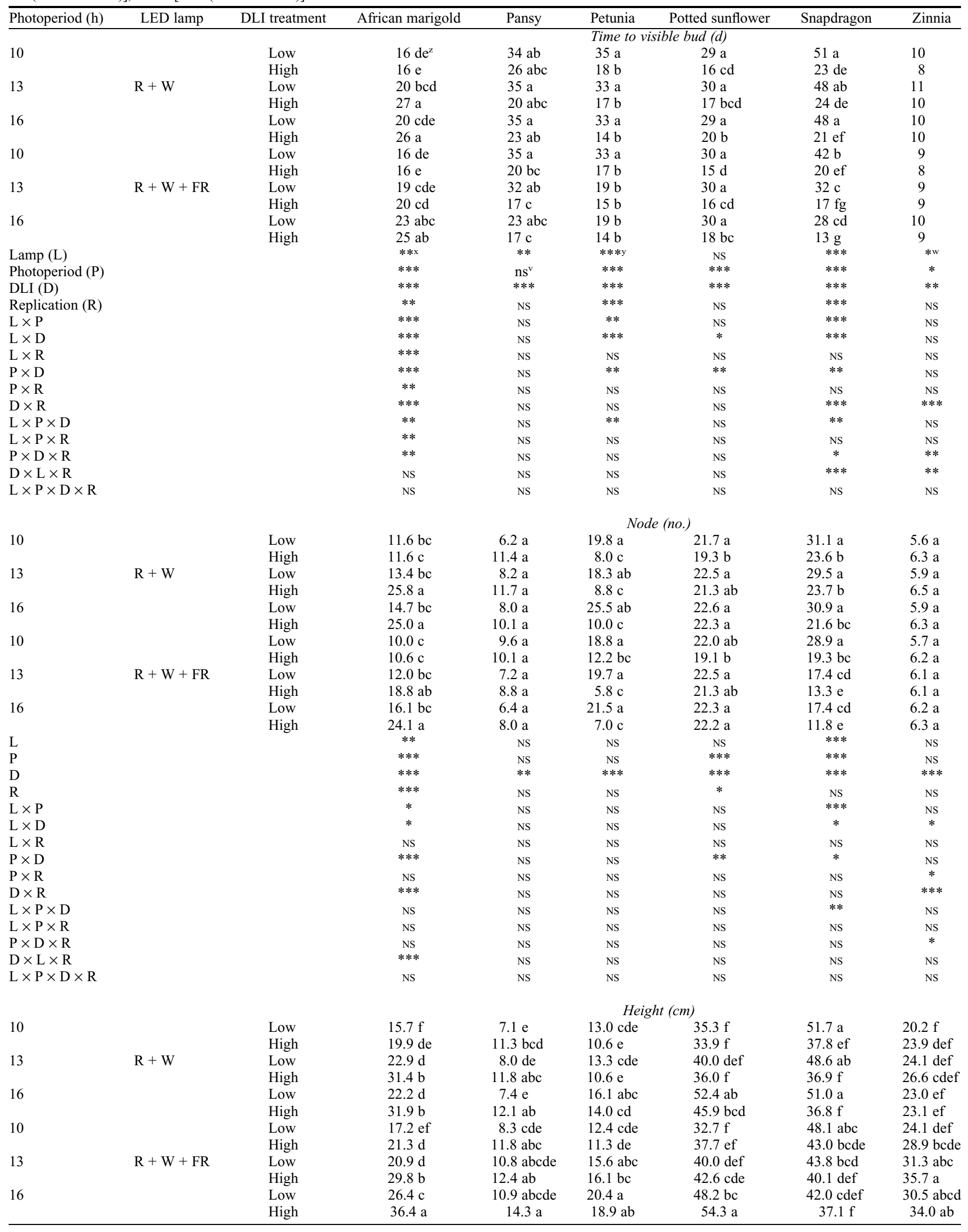


Table 2. (Continued) Days to visible flower bud from transplant, node number, and stem length at first flower for six annual ornamental crops grown under low or high photosynthetic daily light integrals (DLIs) and day-extension photoperiodic lighting delivered from low-intensity light-emitting diode (LED) lamps delivering proportions $(\%)$ of red + white $(\mathrm{R}+\mathrm{W})$ or red + white + far-red $(\mathrm{R}+\mathrm{W}+\mathrm{FR})$ radiation were used to extend the photoperiod by $1 \mathrm{~h}[10 \mathrm{~h}(1700-1800 \mathrm{HR})]$, $4 \mathrm{~h}[13 \mathrm{~h}(1700-2100 \mathrm{HR})]$, or $7 \mathrm{~h}[16 \mathrm{~h}(1700-2400 \mathrm{HR})]$.

\begin{tabular}{|c|c|c|c|c|c|c|c|}
\hline Photoperiod (h) & DLI treatment & African marigold & Pansy & Petunia & Potted sunflower & Snapdragon & Zinnia \\
\hline $\mathrm{L}$ & & $* * *$ & $* *$ & $* * *$ & $* *$ & NS & $* * *$ \\
\hline $\mathrm{P}$ & & $* * *$ & $*$ & $* * *$ & $* * *$ & $* *$ & $* * *$ \\
\hline $\mathrm{D}$ & & $* * *$ & $* * *$ & $*$ & $*$ & $* * *$ & $* * *$ \\
\hline $\mathrm{R}$ & & $* * *$ & $*$ & NS & $* *$ & NS & $* * *$ \\
\hline $\mathrm{L} \times \mathrm{P}$ & & $* * *$ & NS & NS & NS & $*$ & $* *$ \\
\hline $\mathrm{L} \times \mathrm{D}$ & & NS & NS & NS & $* * *$ & $* * *$ & NS \\
\hline $\mathrm{L} \times \mathrm{R}$ & & $*$ & NS & NS & NS & NS & $*$ \\
\hline $\mathrm{P} \times \mathrm{D}$ & & $* * *$ & NS & NS & NS & NS & NS \\
\hline $\mathrm{P} \times \mathrm{R}$ & & $*$ & NS & $*$ & NS & NS & $* *$ \\
\hline $\mathrm{D} \times \mathrm{R}$ & & $* * *$ & NS & NS & NS & $*$ & $* * *$ \\
\hline $\mathrm{L} \times \mathrm{P} \times \mathrm{D}$ & & NS & NS & $* * *$ & NS & NS & NS \\
\hline $\mathrm{L} \times \mathrm{P} \times \mathrm{R}$ & & $* *$ & NS & NS & NS & NS & NS \\
\hline $\mathrm{P} \times \mathrm{D} \times \mathrm{R}$ & & NS & NS & NS & NS & $*$ & NS \\
\hline $\mathrm{D} \times \mathrm{L} \times \mathrm{R}$ & & NS & NS & NS & NS & NS & NS \\
\hline $\mathrm{L} \times \mathrm{P} \times \mathrm{D} \times \mathrm{R}$ & & $* * *$ & $* *$ & $* * *$ & $* *$ & NS & $* * *$ \\
\hline
\end{tabular}

${ }^{\mathrm{z}}$ Means within species and columns followed by different letters are significantly different by Tukey's honest significant difference test at $P \leq 0.05$.

${ }^{\text {y }}$ Significant at $P \leq 0.001$.

${ }^{\mathrm{x}}$ Significant at $P \leq 0.05$.

${ }^{\mathrm{w}}$ Significant at $P \leq 0.01$.

${ }^{v}$ Nonsignificant.

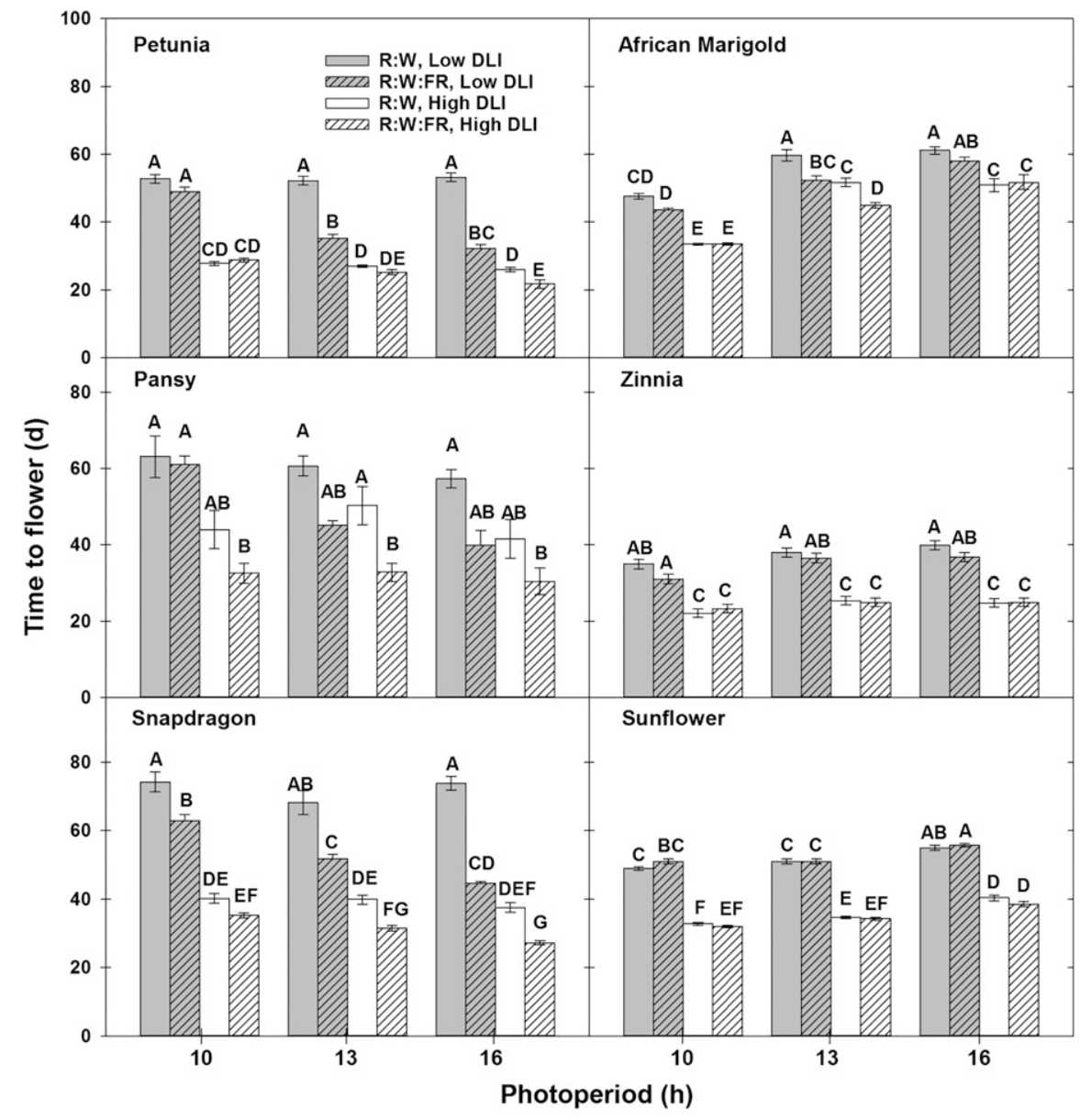

Fig. 2. Days to flower for six annual ornamental crops grown under low or high photosynthetic daily light integrals (DLIs) and day-extension photoperiodic lighting from low-intensity light-emitting diode lamps emitting red + white $(\mathrm{R}+\mathrm{W})$ or red + white + far-red $(\mathrm{R}+\mathrm{W}+\mathrm{FR})$ radiation, which extended the photoperiod by $1 \mathrm{~h}[10 \mathrm{~h}(1700-1800 \mathrm{HR})], 4 \mathrm{~h} \mathrm{[13} \mathrm{h} \mathrm{(1700-2100} \mathrm{HR)],} \mathrm{or} 7 \mathrm{~h} \mathrm{[16} \mathrm{h} \mathrm{(1700-2400} \mathrm{HR)].}$ Values followed by different letters within species are significantly different by Tukey's honest significant difference test at $P \leq 0.05$. Error bars indicate SE.

under high DLIs can be attributed to the interplay of photosynthesis and photoperiod.
An extended photoperiod promoted flowering of petunia and snapdragon only when FR radiation was included in the long daylighting.
Not all long-day plants need FR radiation for photoperiodic control of flowering; the sensitivity to FR radiation can vary among species and cultivars (Runkle et al., 2012). For example, rudbeckia (Rudbeckia hirta L. 'Indian Summer') flowered similarly with and without FR radiation in NI lighting (Meng and Runkle, 2015a). Other plants may not need FR radiation for promotion of flowering but flower most rapidly with additional FR radiation. For example, early flowering occurred in petunia 'Wave Purple Classic' without FR radiation; however, additional FR radiation further promoted flowering (Meng and Runkle, 2015b). In our study, petunia 'Dreams Midnight' and snapdragon 'Oh Snap Pink' showed obligate, FRdependent responses. An intermediate phytochrome photoequilibrium $(\approx 0.67)$ from incandescent lamps or R + FR LEDs was most effective at controlling flowering of plants with FR dependence (Craig and Runkle, 2016). Last, TTF decreased as the photoperiod of FR-containing treatments increased from 10 to $16 \mathrm{~h}$, showing that both the spectrum and photoperiod determine flowering time.

Far-red radiation in DE lighting could interact with the DLI in regulation of flowering; the effect of additional FR radiation was pronounced under low DLIs but diminished under high DLIs, especially for petunia and snapdragon. We confirm that the presence of FR radiation in photoperiodic lighting matters more under low DLIs $\left(<10 \mathrm{~mol} \cdot \mathrm{m}^{-2} \cdot \mathrm{d}^{-1}\right)$ as opposed to high DLIs (Kohyama et al., 2014). This phenomenon may be attributed to the two modes of lightdependent control of flowering through 1) photosynthesis under high-intensity R-rich radiation or 2) phytochromes under lowintensity FR-rich radiation (King et al., 2008). Under a high DLI, increased photosynthesis can be the primary mode to nearly saturate the flowering response. As a result, 
phytochrome-dependent promotion of flowering mediated by low-intensity FR radiation is much less dominant. In contrast, a low DLI may promote flowering to a lesser extent than a high DLI through the photosynthesis-dependent mode, allowing low-intensity FR radiation to modulate phytochromes and accelerate flowering. Supplementing FR radiation under a low DLI reduces the R-to-FR ratio and triggers the shadeavoidance response, which includes accelerated flowering (Franklin and Whitelam, 2005). Phytochromes B, D, and E function redundantly to mediate accelerated flowering of Arabidopsis in an FR-rich environment (Cerdán and Chory, 2003; Franklin et al., 2003; Halliday et al., 1994). A low R-toFR ratio can alleviate the inhibitory role of phytochrome B in flowering and then activate flowering-promoting PHYTOCHROME AND FLOWERING TIME 1 and $F T$ (Cerdán and Chory, 2003). This can explain the promotion of flowering mediated by phytochromes under additional FR in our study.

The photoperiod, lamp type, and DLI all influenced plant height and node number at flowering. Extending the photoperiod from 10 to $16 \mathrm{~h}$ increased the height of african marigold, petunia, and potted sunflower in most lamp type and DLI combinations but had little influence on that of pansy, snapdragon, or zinnia. Similarly, four sunflower cultivars grown under a $16-\mathrm{h}$ photoperiod were $36 \%$ to $76 \%$ taller than those grown under an 8-h photoperiod (Hayata and Imaizumi, 2000). Long days increased node number at flowering of the short-day african marigold and potted sunflower grown under high DLIs, whereas node number of pansy, petunia, and zinnia were similar under different photoperiods, showing species-specific node development. These photoperiodic responses can also be cultivar specific; extending the photoperiod from 11.5 to $16 \mathrm{~h}$ increased the plant height and node number at flowering in $46 \%$ and $43 \%$ of 28 sunflower cultivars, respectively, but not the others (Yañez et al., 2005).

Promotion of stem elongation is a shadeavoidance response observed under a low Rto-FR ratio (Fraser et al., 2016). Reducing the R-to-FR ratio from 147 to 0.66 promoted extension growth of three petunia cultivars and fuchsia (Fuchsia hybrida hort. Ex Siebold \& Voss) (Craig and Runkle, 2016). In addition, compared with NI lighting from $\mathrm{R}+\mathrm{W}$ LEDs, $\mathrm{R}+\mathrm{W}+\mathrm{FR}$ LEDs increased plant height at flowering of some species such as ageratum (Ageratum houstonianum Mill.) and dianthus (Dianthus chinensis L.), especially under relatively high DLIs of 11.1 to $11.6 \mathrm{~mol} \cdot \mathrm{m}^{-2} \cdot \mathrm{d}^{-1}$ (Kohyama et al., 2014). Similarly, for all species except pansy, we observed greater extension growth under $\mathrm{R}+$ $\mathrm{W}+$ FR LEDs than under $\mathrm{R}+\mathrm{W}$ LEDs, especially under high DLIs or long photoperiods. Long DE lighting under a 13- or 16-h photoperiod allowed the addition of FR radiation to cause sufficient turnover of phytochromes and thus promote extension growth.
Ornamental crops grown under high DLIs can exhibit increased height at flowering, a result of stem elongation and TTF. For example, increasing the DLI from 5 to $25 \mathrm{~mol} \cdot \mathrm{m}^{-2} \cdot \mathrm{d}^{-1}$ increased height at flowering of salvia (Salvia splendens Sellow ex Roem. \& Schult 'Vista Red') and french marigold 'Bonanza Yellow' grown at 14 to $24{ }^{\circ} \mathrm{C}$ (Moccaldi and Runkle, 2007). Similarly, height at flowering of celosia (Celosia argentea L. var. plumosa L. 'Gloria Mix') and seed impatiens (Impatiens walleriana Hook. f. 'Accent Red') grown at 15 to $28{ }^{\circ} \mathrm{C}$ increased as the DLI increased from 8 to $26 \mathrm{~mol} \cdot \mathrm{m}^{-2} \cdot \mathrm{d}^{-1}$ (Pramuk and Runkle, 2005). In our study, african marigolds grown under high DLIs $\left(\approx 17.4 \mathrm{~mol} \cdot \mathrm{m}^{-2} \cdot \mathrm{d}^{-1}\right)$ were $24 \%$ to $44 \%$ taller at flowering than those grown under low DLIs $\left(\approx 8.7 \mathrm{~mol} \cdot \mathrm{m}^{-2} \cdot \mathrm{d}^{-1}\right)$. In addition, our results showed that different DLIs elicited species-specific plant height responses. With increasing DLIs, plant height did not change for petunia or zinnia, increased by $48 \%$ to $59 \%$ for pansy grown under R + W LEDs, and decreased by $24 \%$ to $28 \%$ for snapdragon grown under $\mathrm{R}+\mathrm{W}$ LEDs. Another study also reported varying height responses to DLIs ranging from 5 to $43 \mathrm{~mol} \cdot \mathrm{m}^{-2} \cdot \mathrm{d}^{-1}$ in eight bedding plant species, although these data were collected at a specific time, rather than at flowering (Faust et al., 2005).

We elucidated that the photoperiod, spectral distribution of DE lighting, and DLI all influenced flowering and morphology. The inclusion of FR radiation can promote flowering of long-day plants when the DLI is relatively low $\left(\leq 9 \mathrm{~mol} \cdot \mathrm{m}^{-2} \cdot \mathrm{d}^{-1}\right)$ but had little effect on flowering time under a relatively high DLI $\left(\geq 16 \mathrm{~mol} \cdot \mathrm{m}^{-2} \cdot \mathrm{d}^{-1}\right)$. This interaction between FR radiation and the DLI was likely attributed to regulation of flowering through photosynthesis mediated by high light and phytochromes mediated by low-intensity FR radiation. When delivered for a sufficiently long duration, the addition of FR radiation increased the stem elongation of most species. In addition, increasing the DLI promoted flowering of all species, regardless of their photoperiodic responses, and increased extension growth of some, but not all, species.

\section{Literature Cited}

Blanchard, M.G. and E.S. Runkle. 2010. Intermittent light from a rotating high-pressure sodium lamp promotes flowering of long-day plants. HortScience 45:236-241.

Cerdán, P.D. and J. Chory. 2003. Regulation of flowering time by light quality. Nature 423(6942):881-885

Corbesier, L., P. Lejeune, and G. Bernier. 1998. The role of carbohydrates in the induction of flowering in Arabidopsis thaliana: Comparison between the wild type and a starchless mutant. Planta 206(1):131-137.

Craig, D.S. and E.S. Runkle. 2013. A moderate to high red to far-red light ratio from lightemitting diodes controls flowering of shortday plants. J. Amer. Soc. Hort. Sci. 138: 167-172.
Craig, D.S. and E.S. Runkle. 2016. An intermediate phytochrome photoequilibria from nightinterruption lighting optimally promotes flowering of several long-day plants. Environ. Expt. Bot. 121:132-138.

Faust, J.E., V. Holcombe, N.C. Rajapakse, and D.R. Layne. 2005. The effect of daily light integral on bedding plant growth and flowering. HortScience 40:645-649.

Franklin, K.A., U. Praekelt, W.M. Stoddart, O.E. Billingham, K.J. Halliday, and G.C. Whitelam. 2003. Phytochromes B, D, and E act redundantly to control multiple physiological responses in Arabidopsis. Plant Physiol. 131:1340-1346.

Franklin, K.A. and G.C. Whitelam. 2005. Phytochromes and shade-avoidance responses in plants. Ann. Bot. 96(2):169-175.

Fraser, D.P., S. Hayes, and K.A. Franklin. 2016. Photoreceptor crosstalk in shade avoidance. Curr. Opin. Plant Biol. 33:1-7.

Halliday, K.J., M. Koornneef, and G.C. Whitelam. 1994. Phytochrome B and at least one other phytochrome mediate the accelerated flowering response of Arabidopsis thaliana L. to low red/far-red ratio. Plant Physiol. 104(4):1311-1315.

Hayata, Y. and Y. Imaizumi. 2000. Effect of photoperiod on flower bud development of ornamental sunflowers (Helianthus annuиs L.). J. Jpn. Soc. Hort. Sci. 69(6):708-710.

King, R.W., T. Hisamatsu, E.E. Goldschmidt, and C. Blundell. 2008. The nature of floral signals in Arabidopsis. I. Photosynthesis and a far-red photoresponse independently regulate flowering by increasing expression of FLOWERING LOCUS T (FT). J. Expt. Bot. 59(14):38113820.

Kohyama, F., C. Whitman, and E.S. Runkle. 2014. Comparing flowering responses of long-day plants under incandescent and two commercial light-emitting diode lamps. HortTechnology 24:490-495.

Meng, Q. and E.S. Runkle. 2015a. Lowintensity blue light in night-interruption lighting does not influence flowering of herbaceous ornamentals. Scientia Hort. 186:230-238.

Meng, Q. and E.S. Runkle. 2015b. The role of blue light in night-interruption lighting of petunia. Acta Hort. 1107:101-105.

Meng, Q. and E.S. Runkle. 2017. Moderateintensity blue radiation can regulate flowering, but not extension growth, of several photoperiodic ornamental crops. Environ. Expt. Bot. 134C:12-20.

Moccaldi, L.A. and E.S. Runkle. 2007. Modeling the effects of temperature and photosynthetic daily light integral on growth and flowering of Salvia splendens and Tagetes patula. J. Amer. Soc. Hort. Sci. 132:283288.

Oh, W., I.H. Cheon, K.S. Kim, and E.S. Runkle. 2009. Photosynthetic daily light integral influences flowering time and crop characteristics of Cyclamen persicum. HortScience 44:341-344.

Pramuk, L.A. and E.S. Runkle. 2005. Modeling growth and development of celosia and impatiens in response to temperature and photosynthetic daily light integral. J. Amer. Soc. Hort. Sci. 130:813-818.

Runkle, E.S., R.D. Heins, A.C. Cameron, and W.H. Carlson. 1998. Flowering of herbaceous perennials under various night interruption and cyclic lighting treatments. HortScience 33:672-677. 
Runkle, E.S., S.R. Padhye, W. Oh, and K. Getter. 2012. Replacing incandescent lamps with compact fluorescent lamps may delay flowering. Scientia Hort. 143:56-61.

Sager, J.C., W.O. Smith, J.L. Edwards, and K.L. Cyr. 1988. Use of spectral data to determine photosynthetic efficiency and phytochrome photoequilibria. Trans. Amer. Soc. Agr. Eng. 31:1882-1889.
Sheldon, C.C., E.J. Finnegan, D.T. Rouse, M. Tadege, D.J. Bagnall, C.A. Helliwell, W.J. Peacock, and E.S. Dennis. 2000. The control of flowering by vernalization. Curr. Opin. Plant Biol. 3(5):418-422.

Thomas, B. and D. Vince-Prue. 1997. Photoperiodism in plants. 2nd ed. Academic Press, San Diego, CA.

Whitman, C.M., R.D. Heins, A.C. Cameron, and W.H. Carlson. 1998. Lamp type and irradiance level for daylength extensions influence flowering of Campanula carpatica 'Blue Clips', Coreopsis grandiflora 'Early Sunrise', and $\mathrm{Co}$ reopsis verticillata 'Moonbeam'. J. Amer. Soc. Hort. Sci. 123:802-807.

Yañez, P., H. Ohno, and K. Ohkawa. 2005. Photoperiodic response and vase life of ornamental sunflower cultivars. HortTechnology 15:386-390. 